\title{
Circulating and Disseminated Tumour Cells in Breast Carcinoma
}

\author{
Report from the Consensus Conference on Tumour Cell Dissemination during the \\ 38th Annual Meeting of the German Society of Senology, Berlin, 14 June 2018
}

\section{Zirkulierende und disseminierte Tumorzellen beim Mammakarzinom}

\author{
Bericht von der Konsensuskonferenz Tumorzelldissemination im Rahmen der \\ 38. Jahrestagung der Deutschen Gesellschaft für Senologie, Berlin, 14.06.2018
}

(우요 $(2) \Theta$

Authors

Malgorzata Banys-Paluchowski ${ }^{1}$, Andreas Hartkopf ${ }^{2}$, Franziska Meier-Stiegen ${ }^{3}$, Wolfgang Janni ${ }^{4}$,

Erich-Franz Solomayer ${ }^{5}$, Tanja Fehm ${ }^{3}$

Affiliations

1 Frauenklinik, Asklepios-Klinik Barmbek, Hamburg, Germany

2 Universitäts-Frauenklinik, Universitätsklinikum Tübingen, Tübingen, Gemany

3 Klinik für Frauenheilkunde und Geburtshilfe, Universitätsklinikum Düsseldorf, Düsseldorf, Germany

4 Frauenklinik, Universitätsklinikum Ulm, Ulm, Germany

5 Klinik für Frauenheilkunde, Geburtshilfe und Reproduktionsmedizin, Universitätsklinikum des Saarlandes, Homburg/Saar, Germany

Key words

tumour cell dissemination, circulating tumour cells, disseminated tumour cells, breast carcinoma

Schlüsselwörter

Tumorzelldissemination, zirkulierende Tumorzellen, disseminierte Tumorzellen, Mammakarzinom

received 22.9.2018

accepted 4.10.2018

Bibliography

DOI https://doi.org/10.1055/a-0753-7331

Published online 14.1. 2019 | Geburtsh Frauenheilk 2019; 79:

177-183 @ Georg Thieme Verlag KG Stuttgart · New York | ISSN 0016-5751

Correspondence

Dr. med. M. Banys-Paluchowski

Frauenklinik, Asklepios-Klinik Barmbek

Rübenkamp 220, 22307 Hamburg, Germany

banys.malgorzata@yahoo.com
$\Theta$ Deutsche Version unter: https://doi.org/10.1055/a-0753-7331

\begin{abstract}
Haematogenic dissemination of tumour cells in breast carcinoma is among the most intensively researched areas in translational oncology. Large meta-analyses have shown the prognostic relevance of the disseminated tumour cells in the bone marrow and circulating tumour cells in the peripheral blood in the adjuvant as well as metastatic setting. The current status of the research was discussed in detail during the annual meeting of the German Society of Senology in Berlin. The following conference report gives an overview of the clinical study landscape and the new methodological developments for improving the detection and phenotyping of the circulating and disseminated tumour cells.
\end{abstract}

\section{ZUSAMMENFASSUNG}

Hämatogene Dissemination von Tumorzellen bei Mammakarzinom gehört zu den am intensivsten erforschten Gebieten der translationalen Onkologie. Große Metaanalysen haben die prognostische Relevanz der disseminierten Tumorzellen im Knochenmark und der zirkulierenden Tumorzellen im peripheren Blut sowohl in der Adjuvanz als auch im metastasierten Setting gezeigt. Im Rahmen der Jahrestagung der Deutschen Gesellschaft für Senologie in Berlin wurde der aktuelle Stand der Forschung intensiv diskutiert. Der folgende Kongressbericht gibt einen Überblick über die klinische Studienlandschaft und die neuen methodischen Entwicklungen zur Verbesserung der Detektion und der Phänotypisierung der zirkulierenden und disseminierten Tumorzellen. 


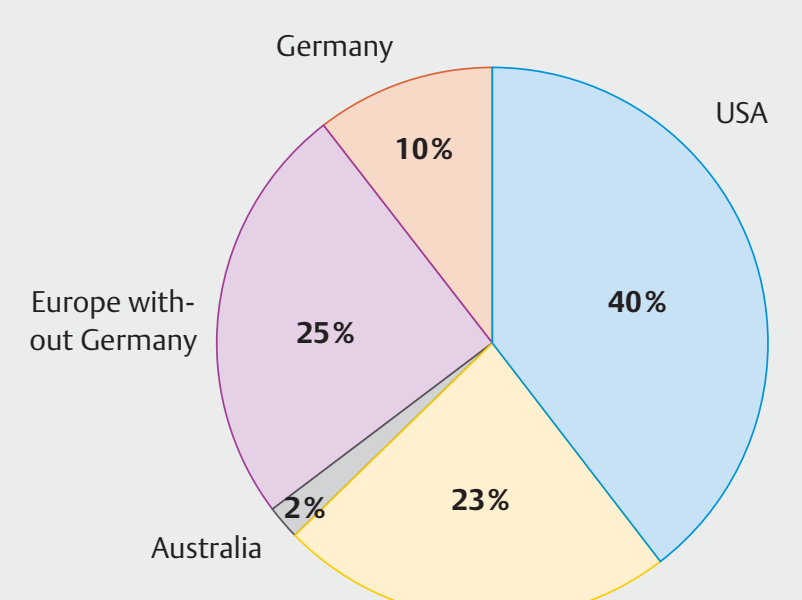

Asia

- Fig. 1 CTCs and DTCs - current study landscape.

\section{Introduction}

Haematogenic tumour cell dissemination in solid tumours is currently among the most intensively researched areas in translational oncology. There is a particular focus on breast carcinoma due to the multitude of study projects. Large international meta-analyses have already confirmed the prognostic relevance of the disseminated tumour cells (DTCs) in the bone marrow and circulating tumour cells (CTCs) in the peripheral blood in adjuvant treatment and also in the metastatic setting [1-4]. The extent to which the detection and the characteristics of these tumour cells can contribute to the further individualisation of therapy is currently being investigated. There are presently 53 clinical studies registered in the ClinicalTrials.gov and EudraCT registries which are either already recruiting or will soon be initiated. The overwhelming majority (47 studies) focuses on the circulating tumour cells in the blood; only six studies concern DTCs in the bone marrow. Worldwide, the USA, with $40 \%$ of the studies, is the most highly represented, while $35 \%$ of the studies are being initiated in Europe, one out of every 10 in Germany ( $\triangleright$ Fig. 1). Germany has a leading position particularly in the area of the studies which could soon be adopted in everyday clinical practice: two out of five registered phase III studies are being conducted in this country - both within the scope of the DETECT study programme.

Exciting results from the translational studies on tumour cell dissemination were recently presented at the international conferences (ASCO, San Antonio Breast Cancer Symposium and $E B C C)$. The current status of the research was discussed in detail at the annual meeting of the German Senology Society in Berlin. Below, we would like to provide you with an overview of the clinical study landscape and the new methodological developments for improving the detection and phenotyping of CTCs/DTCs.

\section{Methods for the Detection of Circulating and Disseminated Tumour Cells}

The detection and the subsequent molecular characterisation of CTCs are characterised by two major challenges. On the one hand, the concentration of these cells is in the range between 1 and $10^{7}$ cells per litre of blood and this is thus only a fraction of the concentrations of other cells in the blood. By contrast, when isolating according to physical criteria such as, for example, size or density, overlaps with the other cell populations are largely seen. Another challenge arises from the heterogeneity of the CTCs. While the reproducible sensitive proof of CTCs was in the foreground in the previous detection methods, the question of characterisation of the cells and thus the predictive relevance is becoming more and more important.

The current gold standard for the detection of CTCs is the CellSearch ${ }^{\circledR}$ system (Menarini Silicon Biosystems, Italy) [5]. It is based on the immunomagnetic enrichment of EpCAM-positive cells and their characterisation as CTCs through the detection of cytokeratin and DAPI as well as the exclusion of the leukocyte marker CD45. An alternative approach to CellSearch ${ }^{\circledR}$ is the IsoFlux system $^{\mathrm{TM}}$ which is based on the combination of immunomagnetic separation, for example, EpCAM+ cells, within a microfluidics system [6]. EpCAM+ cells can also be detected and enriched with the aid of the GILUPI CellCollector ${ }^{\circledR}$ [7]. In this process, a functionalised wire coated with the antibodies directed against EPCAM is positioned for a certain amount of time in the peripheral vein. The bound CTCs can be identified and characterised on the wire using immunofluorescence [8]. The Parsortix ${ }^{\mathrm{TM}}$ system, for example, is marker-independent and thus suitable for identifying EpCAM cells which undergo the epithelial-mesenchymal transition and thus do not express their epithelial antigens. The cells are separated based on their size and deformability in a microfluidic system whereby the flow of liquid is directed over steps of different heights and as a result, the comparably larger CTCs are enriched [9]. Along with independent purification methods, there is another option to supplement CellSearch ${ }^{\circledR}$ and thus the establishment of workflows for a more comprehensive analysis of the CTCs on the single cell level.

With the exception of the GILUPI CellCollector ${ }^{\circledR}$, the alternatives and supplements to the CellSearch ${ }^{\circledR}$ system presented so far are all based on the analysis of a few millilitres of peripheral blood. In the primary situation above all, this results in a low rate of positivity in the detection of the rare CTCs and a low possibility in this situation of using the phenotype of the CTCs as the basis of therapeutic decisions. The development of diagnostic leukapheresis (DLA) enables the analysis of larger volumes of blood (median processed volume 2.6 litres) and thus a higher number of CTCs to be characterised. DLA is performed analogously to therapeutic leukapheresis with the difference that the mobilisation of stem cells through the administration of growth factors is not necessary. CTCs could be detected in $72 \%$ of the leukapheresis specimens investigated from patients with carcinoma of various entities; in corresponding blood specimens, the rate of positivity was only $28 \%$ [10]. 


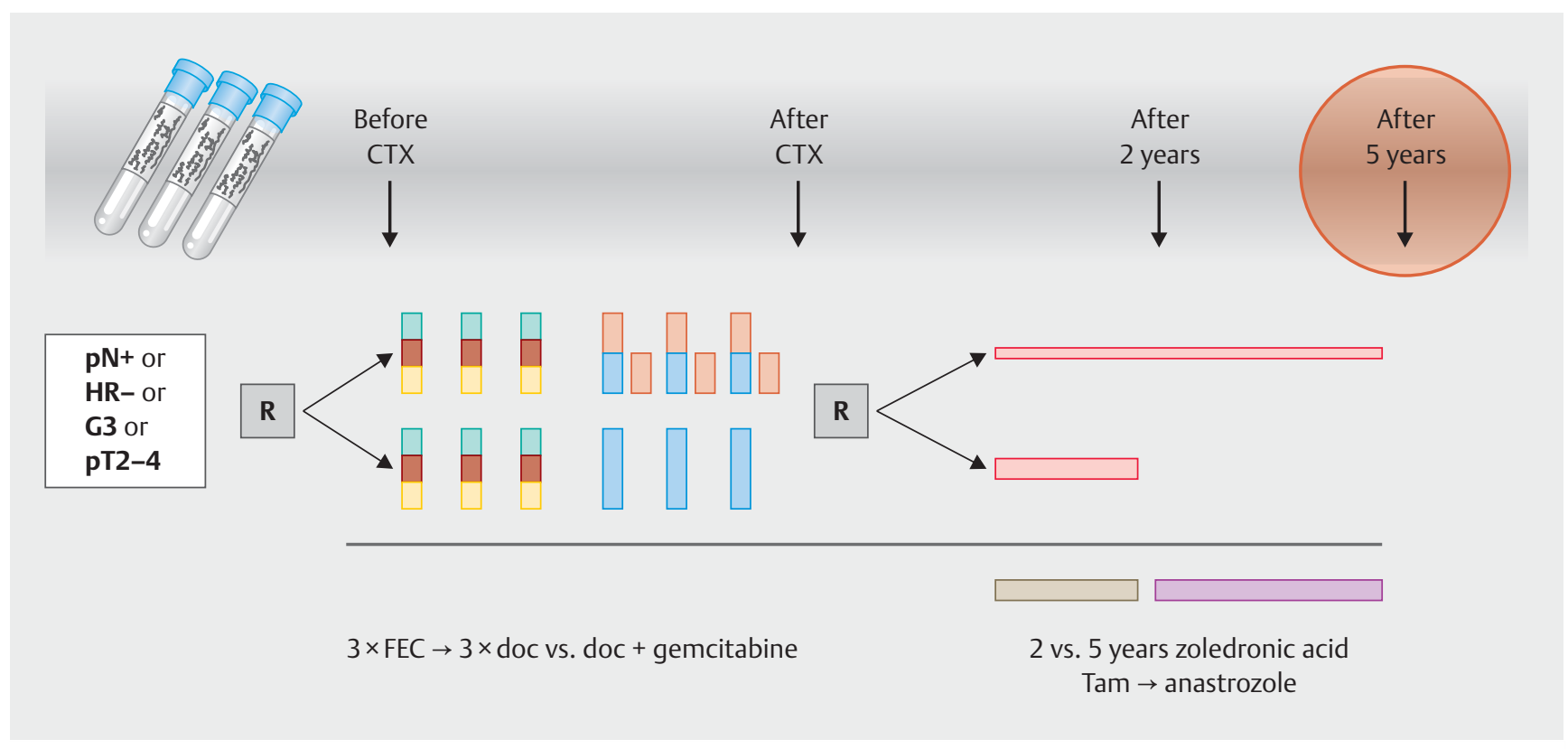

- Fig. 2 CTCs were determined at different points in time within the scope of the translational research programme of the SUCCESS-A study.

\section{Tumour Cell Dissemination in Non-Metastatic Breast Carcinoma}

The detection of tumour cells in the blood and/or bone marrow at initial diagnosis was confirmed in large meta-analyses as an independent predictor of a worse clinical outcome [1,3]. Patients who have persistent CTCs/DTCs after completing (neo)adjuvant chemotherapy also have an increased risk of recurrence $[11,12]$. However, to date, there has not been any reliable marker for monitoring the individual risk of disease recurrence (and thus indirectly also the efficacy of the adjuvant systemic endocrine therapy) during aftercare. Therefore circulating markers in the peripheral blood (a so-called "liquid biopsy") which can predict the recurrence of the disease early on are sought. Two studies were recently presented here which prospectively investigated the extent to which CTC detection during aftercare influences the prognosis.

At the SABCS 2017, Sparano et al. presented data from the ECOG-ACRIN study E5103 $[13,14]$. Within the scope of this study, HER2-negative patients with stage II-III breast cancer received adjuvant therapy with AC followed by docetaxel \pm bevacizumab. About five years (4.5-7.5 years, median: 5.2 years) after primary diagnosis, CTCs were identified in the blood using CellSearch. Of 546 patients, $4.8 \%$ had at least one CTC/7.5 ml blood. The positivity rate was $4.3 \%$ in the case of the hormone-receptor-negative patients and $5.1 \%$ among the hormone-receptor-positive patients. After an average follow-up period of 1.6 years, CTC detection was associated with a risk of recurrence that was 18 times as high $(p=0.01)$. The average time until the appearance of the recurrence in the case of CTC positivity was 2.8 years. In the multivariate analysis, the CTC status was the strongest predictor of disease recurrence.

Within the scope of the comprehensive biomarker program of the German SUCCESS-A, Rack et al. were able to show that the
CTC status has prognostic relevance both before and also after chemotherapy ( $\bullet$ Fig. 2) [11]. At this year's annual ASCO meeting, the data on the prognostic relevance of a CTC determination five years after completing primary treatment were presented [15]. In 206 patients, a blood sample was tested using CellSearch after an average period of 62 months. At least one CTC/7.5 ml blood could be detected in $7.8 \%$ of the patients. After an average follow-up of 360 days, there were 13 recurrences. In the hormone-receptor-positive subgroup, the CTC status was significantly associated with worse disease-free survival (hazard ratio 5.95, 95\% confidence interval: $1.14-31.16, p=0.035$ ).

The data from the E5103 as well as the SUCCESS study showed that the risk of recurrence can be monitored using CTC detection. Additional studies now need to show whether effective therapeutic consequences can be derived from this finding.

\section{CTCs as a basis for a therapeutic decision in early breast carcinoma}

Adjuvant systemic therapy is currently still oriented towards the characteristics of the primary tumour. However, if the hormone receptor and HER2 status of metastases are investigated, a different receptor status is often found. This subject was investigated in two recently presented studies:

At the San Antonio Breast Cancer Symposium (SABCS) 2017, Aktas et al. presented an investigation of the expression profiles of the primary tumour, lymph node metastases and circulating tumour cells (detected using AdnaTest BreastCancer) [16]. Using 76 cases, the authors were able to show that the receptor status of the circulating tumour cells significantly differs from the primary tumour (concordance rates for ER/PR/HER2: 16\%/25\%/ $71 \%$ ) and LN metastases (concordance rates for ER/PR/HER2: $14 \% / 25 \% / 70 \%)$. In the future, prospective randomised studies should investigate the extent to which circulating tumour cells al- 


\section{GeparX: Investigating Denosumab as an add-on neoadjuvant treatment for RANK/L-positive or RANK/L-negative primary breast cancer and two different nab-Paclitaxel schedules; $2 \times 2$ factorial design}

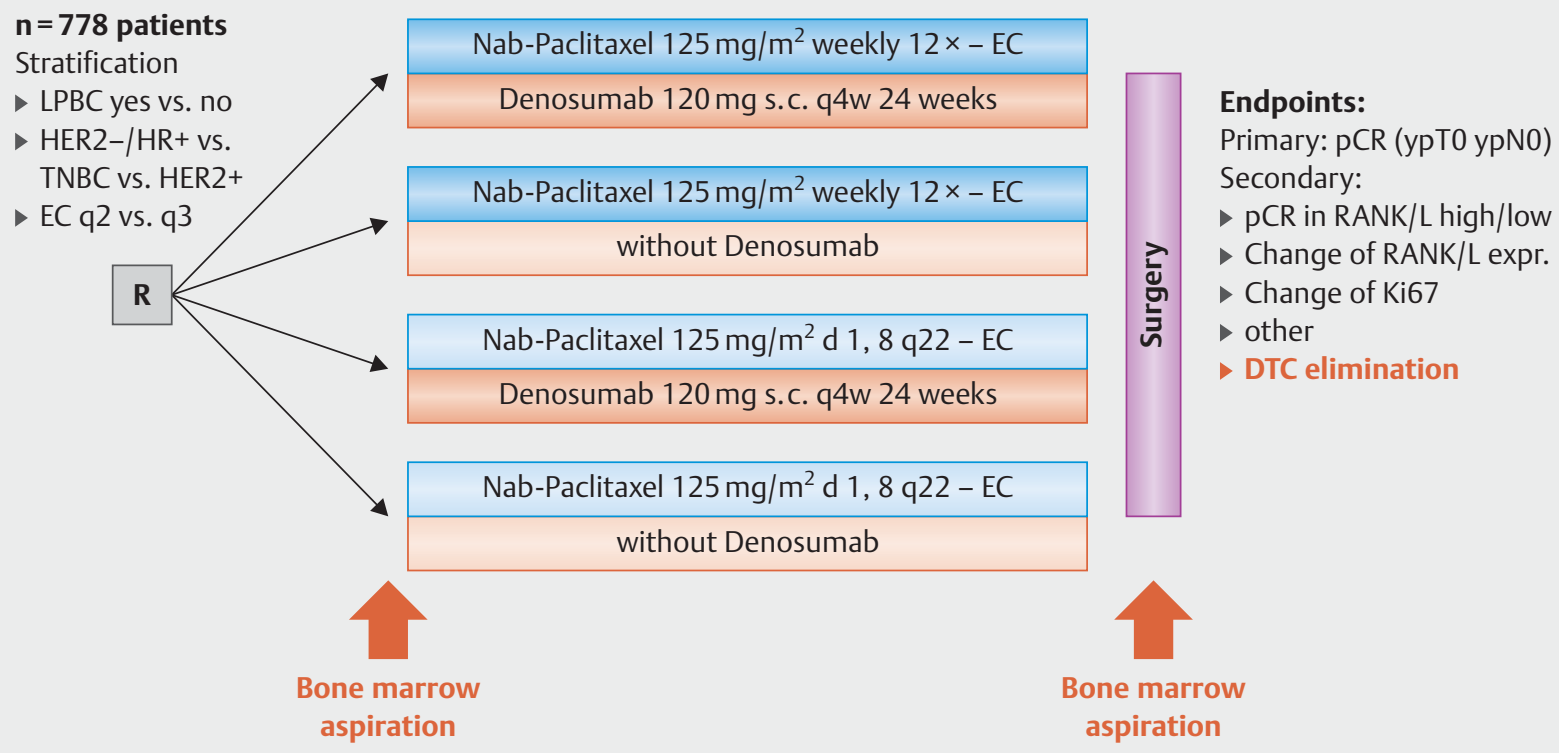

Fig. 3 Study design of the GeparX study taking the DTC substudy into account.

low a decision regarding targeted therapy options (e.g. hormone therapy, HER2-targeted therapy).

The long-awaited results of the European TREAT CTC study were presented at the European Breast Cancer Conference in Barcelona in March 2018. This study was intended to investigate whether the HER2-targeted therapy can eliminate persistent CTCS in patients with HER2-negative primary tumours [17]. Within the scope of this randomised phase II study, 1317 patients were screened after completing (neo)adjuvant chemotherapy. In $7.2 \%$ of them, at least one CTC was able to be detected using the CellSearch $^{\circledR}$ system. Thirty-one patients in the intervention arm received six administrations of trastuzumab every 3 weeks, 32 patients were in the control arm. The CTC positivity rate after 18 weeks was similar in both arms $(17.2 \%$ in the trastuzumab arm, $13.8 \%$ in the control arm); no difference was able to be determined in invasive disease-free survival either, and thus the study recruitment was not continued after the interim analysis. One possible explanation for this negative result could be the lack of phenotyping of the tumour cells. The HER2 status of the CTCS was determined within the scope of the study but did not play any role in study inclusion; $76 \%$ of the recruited patients demonstrated only HER2-negative CTCs at the screening blood draw.

\section{The clinical significance of DTCs in the bone marrow in the case of early breast carcinoma}

The detection of DTCs in the bone marrow is an independent prognostic marker in women with primary breast carcinoma. These micrometastases which can be detected as DTCs in the bone marrow can develop in the very early stages of breast cancer [18]. Clinical evidence for this hypothesis can be found, among others, in a ma- jor analysis of the American SEER registry which was able to show that, of more than 100000 patients with pure DCIS, about 500 patients died of metastatic breast cancer without previously experiencing invasive local recurrence [19]. At the SABCS 2017, Walter et al. presented an analysis of the DTC status of 672 patients suffering from pure DCIS. DTCs were able to be detected in 72 patients (11\%) [20]. The detection of at least 2 DTCs $/ 2 \times 10^{6}$ mononuclear bone marrow cells was significantly associated with an increased risk of local recurrence $(p=0.033)$. A trend was also seen in relation to the survival without recurrent distant metastases and overall survival which, however, was not statistically significant in regard to the few events. Molecular genetic investigations on single cell level now need to show whether the DTCs found actually arise from the preinvasive lesion or whether very small, already invasive portions may be responsible for the tumour cell dissemination.

One of the few studies currently recruiting which is focusing on tumour cell dissemination in the bone marrow is the translational supporting programme of the randomised GeparX study (NCT02682693, EudraCT 2015-001755-72). The bisphosphonate-based studies have already been able to show that zoledronic acid can very effectively eliminate DTCs from the bone marrow [21]. The GeparX study, which is being jointly conducted by the study groups AGO-B and the German Breast Group, intends to clarify whether the RANKL inhibitor denosumab has a similar activity. This phase Ilb study is investigating whether the addition of denosumab to the neoadjuvant chemotherapy can improve the rate of complete remissions. At the same time, the bone marrow status is evaluated in the DTC substudy of the bone marrow status to check whether denosumab can inhibit the persistence of disseminated tumour cells ( $\triangleright$ Fig. 3 ). 


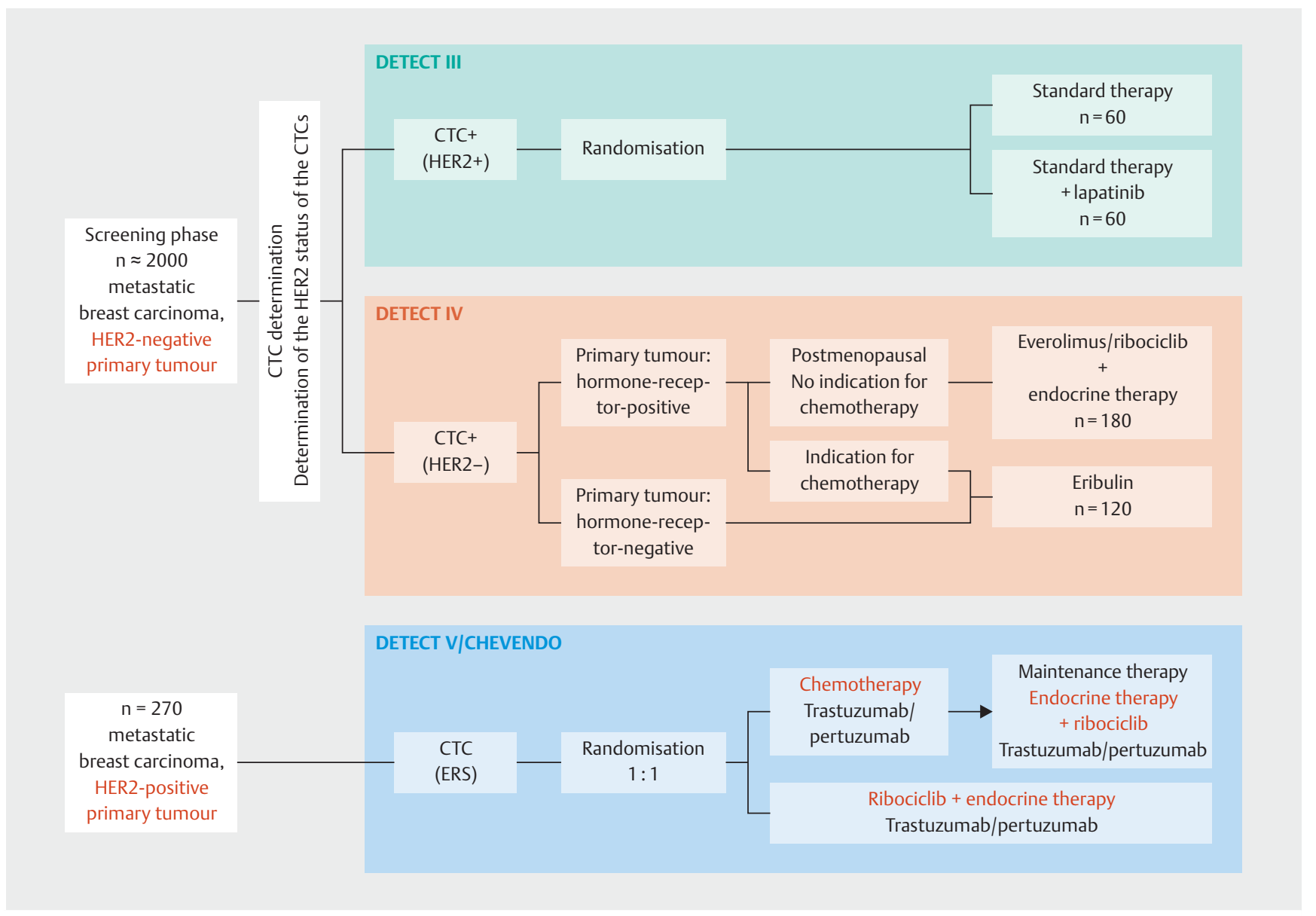

- Fig. 4 Study design of the DETECT studies.

\section{Tumour Cell Dissemination in Metastatic Breast Carcinoma}

In the metastatic setting, CTCs were confirmed in several analyses as an independent prognostic factor [2].In addition, the CTC status indicates the response to therapy early on during palliative chemotherapy [22]. The current studies focus on the CTC-based therapeutic interventions [23]. Two exciting study programmes are currently evaluating the potential of CTCs in this context: the French project is being coordinated by the Institut Curie in Paris and the German project is being coordinated by the DETECT study group.

In the CirCe T-DM1 study, the use of trastuzumab-DM1 was investigated in patients with HER2-negative breast carcinoma. Unlike in the TREAT CTC study, only women with HER2-amplified CTCs were able to participate in the study. One hundred fifty-five patients who were in part heavily pretreated were screened; in 9.2\%, at least one HER2-positive CTC was detected [24]. Of 11 patients treated with T-DM1, only one of them achieved partial remission and thus the authors conclude that the therapeutic approach tested is not promising. The very low prevalence of HER2- amplified CTCs was discussed as a possible explanation: a median of only $1.6 \%$ of the CTCs detected had a positive HER2 status.

In the second French study, STIC CTC (NCT01710605), the choice of therapy is not based on the characteristics of the CTCS but rather on the cell count. The objective is to recruit 994 patients with newly diagnosed metastatic breast carcinoma, hormone-receptor-positive, HER2-negative, who are to begin their first-line therapy. A blood sample from all patients was tested for CTCs using the CellSearch ${ }^{\circledR}$ system before the start of therapy. Women in the control arm receive the therapy recommended by their oncologist (chemotherapy or endocrine therapy). The treatment is determined via the CTC status in the intervention arm: women with $\geq 5 \mathrm{CTCs} / 7.5 \mathrm{ml}$ blood receive chemotherapy, those with $<5$ CTCs receive endocrine therapy. An interim analysis after including 530 patients revealed that the CTC-based approach leads to a change in therapy in $38 \%$ of cases. The study is no longer recruiting, the survival data are pending. However, through the introduction of the CDK4/6 inhibitors, it remains unclear how the possible results could be included in clinical practice.

The largest study program in the world on a CTC-based therapeutic intervention is the German DETECT project which includes two phase III and one phase II study [25] ( Fig. 4). Currently, systemic therapy in a metastatic setting depends only on the charac- 
- Table 1 Tumour cell dissemination in the case of breast carcinoma: the latest knowledge.

\begin{tabular}{|c|c|c|}
\hline & Early breast carcinoma & Metastatic breast carcinoma \\
\hline $\begin{array}{l}\text { Prognostic } \\
\text { relevance }\end{array}$ & $\begin{array}{l}\text { yes (level I evidence) } \\
\text { Both DTCs and CTCs are an independent prognostic factor } \\
\text { for disease-free and overall survival }[1,3] \text {. } \\
\text { CTCs before the start of neoadjuvant chemotherapy } \\
\text { do not correlate with the response }[4] \text {. }\end{array}$ & $\begin{array}{l}\text { yes (level I evidence) } \\
\text { High numbers of CTCs correlate with shortened progres- } \\
\text { sion-free and overall survival; unlike in the case of early } \\
\text { breast carcinoma, the cut-off value of } 5 \text { CTCs } 7.5 \text { ml blood is } \\
\text { used here [2]. }\end{array}$ \\
\hline Therapy monitoring & $\begin{array}{l}\text { potentially relevant } \\
\text { Detection of CTCs upon completion of neoadjuvant } \\
\text { treatment is associated with a worse outcome [4]. } \\
\text { In hormone-receptor-positive breast carcinoma, the CTC } \\
\text { detection during aftercare } 2 \text { and } 5 \text { years after diagnosis } \\
\text { correlates with the prognosis }[14,15] \text {. }\end{array}$ & $\begin{array}{l}\text { potentially relevant } \\
\text { Increased numbers of CTCs during therapy predict an } \\
\text { unfavourable response, but patients do not benefit in the } \\
\text { previous studies from an early switch to another therapy } \\
\text { [22]. }\end{array}$ \\
\hline $\begin{array}{l}\text { Therapy choice } \\
\text { based on } \\
\text { CTCs/DTCs }\end{array}$ & $\begin{array}{l}\text { unclear } \\
\text { no benefit of trastuzumab therapy in patients with persis- } \\
\text { tent CTCs in the TREAT CTC study (however without taking } \\
\text { the HER2 status of the CTCs into account) [17] }\end{array}$ & $\begin{array}{l}\text { potentially relevant } \\
\text { no benefit of administering T-DM1 in patients with } \\
\text { histologically HER2-negative disease but HER2-positive } \\
\text { CTCs [24] } \\
\text { Results of other studies are pending (in particular the } \\
\text { DETECT study programme) [25]. }\end{array}$ \\
\hline
\end{tabular}

teristics of the primary tumour or the metastasis. In the event of a discrepancy between the tumour and the CTCs, the status of the cells detected in the blood ("liquid biopsy") is still not taken into account. Therefore the DETECT III study is investigating whether women with HER2-negative metastatic disease but with detection of HER2-positive CTCs benefit from the addition of lapatinib to standard therapy. Patients with exclusively HER2-negative CTCS can be treated within the scope of the DETECT IV study with eribulin or endocrine therapy with ribociclib or everolimus.

The randomised DETECT $V$ study is aimed at patients with HER2-positive, hormone-receptor-positive disease in the metastatic stage. Patients receive the dual antibody blockade in combination with chemotherapy or endocrine therapy. The therapy options will shortly be expanded to include the CDK4/6 inhibitor ribociclib. The study should clarify whether the CTC status can identify those patients in whom chemotherapy can reliably be dispensed with.

\section{Outlook}

According to the latest data, circulating tumour cells have the potential to be widely used in everyday clinical practice ( $\bullet$ Table 1 ). Two recently published studies - one was conducted in Germany, the other primarily in the USA - were able to demonstrate that the detection of CTCs during aftercare following hormone-receptorpositive breast carcinoma can identify patients with a significantly increased risk for a late relapse. In this setting, CTC detection could possibly facilitate the decision for or against expanded endocrine therapy beyond the fifth year and additionally allow the possible need for longer aftercare to be better assessed. This needs to be evaluated in future studies.

Even in a metastatic situation, the potential of CTC-based diagnostics remains clear. The connection between the detection of CTCs during palliative chemotherapy and a worse response was already proven with very good evidence. However, the possible therapeutic consequence which should be derived from the investigation of the "liquid biopsy" remains unclear. Can we use the phenotype of the CTCs as a basis for selecting therapy? Do patients with high CTC counts need more intensive treatment? These questions are currently being clarified in the German DETECT studies, the largest study project in the world on CTC-based therapeutic interventions.

\section{Conflict of Interest}

The authors declare that they have no conflict of interest.

\section{References}

[1] Braun S, Vogl FD, Naume B et al. A pooled analysis of bone marrow micrometastasis in breast cancer. N Engl J Med 2005; 353: 793-802

[2] Bidard FC, Peeters DJ, Fehm T et al. Clinical validity of circulating tumour cells in patients with metastatic breast cancer: a pooled analysis of individual patient data. Lancet Oncol 2014; 15: 406-414

[3] Janni W], Rack B, Terstappen LW et al. Pooled Analysis of the Prognostic Relevance of Circulating Tumor Cells in Primary Breast Cancer. Clin Cancer Res 2016; 22: 2583-2593

[4] Bidard FC, Michiels S, Riethdorf S et al. Circulating Tumor Cells in Breast Cancer Patients Treated by Neoadjuvant Chemotherapy: A Meta-analysis. J Natl Cancer Inst 2018; 110: 560-567

[5] Park Y, Kitahara T, Urita T et al. Expected clinical applications of circulating tumor cells in breast cancer. World J Clin Oncol 2011; 2: 303-310

[6] Harb W, Fan A, Tran T et al. Mutational Analysis of Circulating Tumor Cells Using a Novel Microfluidic Collection Device and qPCR Assay. Transl Oncol 2013; 6: 528-538

[7] Saucedo-Zeni N, Mewes S, Niestroj R et al. A novel method for the in vivo isolation of circulating tumor cells from peripheral blood of cancer patients using a functionalized and structured medical wire. Int J Oncol 2012; 41: 1241-1250 
[8] Gorges TM, Penkalla N, Schalk T et al. Enumeration and Molecular Characterization of Tumor Cells in Lung Cancer Patients Using a Novel In Vivo Device for Capturing Circulating Tumor Cells. Clin Cancer Res 2016; 22: 2197-2206

[9] Hvichia GE, Parveen Z, Wagner C et al. A novel microfluidic platform for size and deformability based separation and the subsequent molecular characterization of viable circulating tumor cells. Int J Cancer 2016; 138: 2894-2904

[10] Fischer JC, Niederacher D, Topp SA et al. Diagnostic leukapheresis enables reliable detection of circulating tumor cells of nonmetastatic cancer patients. Proc Natl Acad Sci U S A 2013; 110: 16580-16585

[11] Rack B, Schindlbeck C, Jückstock J et al. Circulating tumor cells predict survival in early average-to-high risk breast cancer patients. J Natl Cancer Inst 2014. doi:10.1093/jnci/dju066

[12] Janni W, Vogl FD, Wiedswang G et al. Persistence of disseminated tumor cells in the bone marrow of breast cancer patients predicts increased risk for relapse-a European pooled analysis. Clin Cancer Res 2011; 17: $2967-$ 2976

[13] Sparano JA, O’Neill A, Alpaugh K et al. Circulating tumor cells (CTCs) five years after diagnosis are prognostic for late recurrence in operable stage II-III breast cancer. SABCS 2017; Abstr. GS6-03

[14] Sparano J, O’Neill A, Alpaugh K et al. Association of Circulating Tumor Cells With Late Recurrence of Estrogen Receptor-Positive Breast Cancer: A Secondary Analysis of a Randomized Clinical Trial. JAMA Oncol 2018. doi:10.1001/jamaoncol.2018.2574

[15] Janni W, Rack B, Fasching P et al. Persistence of circulating tumor cells in high risk early breast cancer patients five years after adjuvant chemotherapy and late recurrence: Results from the adjuvant SUCCESS A trial. J Clin Oncol 2018. doi:10.1200/JCO.2018.36.15_suppl.515
[16] Aktas B, Weydandt L, Westerwick D et al. Comparison of HER2, estrogen and progesterone receptor expression profiles of primary tumor, synchronous axillary lymph node metastases and circulating tumor cells in early breast cancer patients. Cancer Res 2018; 78 (4 Suppl.): PD3-02PD3-02

[17] Ignatiadis $M$, Litiere $S$, Rothe $F$ et al. Trastuzumab versus observation for HER2 non amplified early breast cancer with Circulating Tumor Cells (EORTC90091-10093, BIG 1-12, Treat CTC): A randomized phase 2 trial. Ann Oncol 2018. doi:10.1093/annonc/mdy211

[18] Hosseini H, Obradovic MM, Hoffmann M et al. Early dissemination seeds metastasis in breast cancer. Nature 2016. doi:10.1038/nature20785

[19] Narod SA, lqbal J, Giannakeas V et al. Breast Cancer Mortality After a Diagnosis of Ductal Carcinoma In Situ. JAMA Oncol 2015; 1: 888-896

[20] Walter VP, Taran FA, Wallwiener M et al. Detection of disseminated tumor cells in DCIS patients impacts local recurrence. SABCS 2017; Abstr. P1-01-16

[21] Banys M, Solomayer EF, Gebauer G et al. Influence of zoledronic acid on disseminated tumor cells in bone marrow and survival: results of a prospective clinical trial. BMC Cancer 2013; 13: 480

[22] Smerage JB, Barlow WE, Hortobagyi GN et al. Circulating tumor cells and response to chemotherapy in metastatic breast cancer: SWOG S0500. J Clin Oncol 2014; 32: 3483-3489

[23] Banys-Paluchowski M, Krawczyk N, Meier-Stiegen F et al. Circulating tumor cells in breast cancer-current status and perspectives. Crit Rev Oncol Hematol 2016; 97: 22-29

[24] Bidard F-C, Cottu P, Dubot C et al. Anti-HER2 therapy efficacy in HER2negative metastatic breast cancer with HER2-amplified circulating tumor cells: results of the CirCe T-DM1 trial (117P). Ann Oncol 2017; 28: v22-v42

[25] Schramm A, FriedI TW, Schochter F et al. Therapeutic intervention based on circulating tumor cell phenotype in metastatic breast cancer: concept of the DETECT study program. Arch Gynecol Obstet 2016; 293: 271-281 